\title{
Growth of human prostate cancer cells is significantly suppressed in vitro with sodium butyrate through apoptosis
}

\author{
JUN QIU $^{1}$, ZHENLI GAO ${ }^{2}$ and HIROKI SHIMA ${ }^{3}$ \\ Departments of ${ }^{1}$ Blood Purification Center and ${ }^{2}$ Urology, Yantai Yuhuangding Hospital, Qingdao University Medical College, \\ Yantai, Shandong Province, P.R. China; ${ }^{3}$ Department of Urology, Hyogo College of Medicine, Nishinomiya, Japan
}

Received August 10, 2011; Accepted September 8, 2011

DOI: $10.3892 /$ or.2011.1470

\begin{abstract}
Histone deacetylase inhibitors (HDACis) have shown significant antiproliferative and apoptotic properties in various types of cancer cells, including prostate cancer cells, and are therefore being evaluated as a treatment modality. However, the mechanism by which sodium butyrate (SB) induces apoptosis is not completely understood. We focused on SB which exists in the intestine and is therefore expected to have less adverse effects. In this study, three prostate cancer cell lines (LNCaP, DU145 and PC-3) were treated in vitro with different concentrations of SB. Cell proliferation was studied by the XTT assay; cell cycle analysis and induction of apoptosis were studied by laser scanning cytometry. Western blot analysis was used to study p21, p27, CDK2, CDK4, CDK6, caspase-3, caspase-7, Fas, FADD, TRADD, Bcl-2 and Bax protein expression. SB inhibited cell growth and induced apoptosis in a concentration-dependent manner in human prostate cancer cells (LNCaP, DU145 and PC-3). Western blot analysis showed dose-dependent increases of p21 levels in DU145 and PC-3 cells, and dose-dependent decreases of CDK2, CDK4, CDK6 and procaspase- 3 protein levels in all three prostate cancer cell lines. Bcl-xL was significantly down-regulated in DU145 cells, and Bcl-2 was significantly down-regulated in PC-3 and LNCaP cells. No significant changes were observed in procaspase-7, TRADD and Bax expression, although slight decreases in Fas and FADD expression were seen in all three prostate cancer cell lines. Analysis of cell morphology using laser scanning microscopy detected condensed and fragmented nuclei. In conclusion, SB induces G1 and G2 arrest by increasing p21 expression resulting in CDK2, CDK4 and CDK6 down-regulation. SB potently induced apoptosis, which was accompanied by DNA fragmentation, down-regulated Bcl-2 in LNCaP and PC-3 cells, Bcl-xL in DU145 cells, and down-regulated procaspase- 3 , but not procaspase-7, in these
\end{abstract}

Correspondence to: Dr Jun Qiu, Department of Blood Purification Center, Yantai Yuhuangding Hospital, Qingdao University Medical College, Yantai 264000, Shandong Province, P.R. China

E-mail: qiujun536@hotmail.com

Key words: prostate, cancer, sodium butyrate, apoptosis human prostate cancer cell lines. These results suggest that SB may serve as a new modality for the treatment of hormone refractory prostate cancer.

\section{Introduction}

Prostate cancer has the highest incidence and is the second leading cause of cancer-related deaths among men (1). One out of nine men over 65 years of age is diagnosed with prostate cancer in the United States (2). In Japan, the incidence of prostate cancer is also increasing. Most patients who develop metastatic disease initially respond to androgen deprivation, but ultimately develop androgen-independent disease that results in progressive clinical deterioration and death (3). Therapies commonly used for hormone refractory prostate cancer, such as androgen withdrawal, cytotoxic chemotherapy and radiotherapy are relatively nonselective, highly toxic to normal tissues, and rarely curative (4). There is a great need to develop better mechanism-based therapies for prostate cancer.

Accumulating data indicate that many anticancer drugs can cause the death of tumor cells through the induction of apoptosis, which is regarded as the preferred way to manage cancer. Apoptosis plays an important role in the renewal of epithelia in normal and neoplastic prostate, and a reduction of the apoptotic rate has been associated with progression from localized to metastatic cancer $(5,6)$. In addition, increasing evidence indicates that an impaired ability to undergo apoptosis plays an important role in the transition from androgen-dependent to androgen-independent prostate cancer as well as drug resistance (7). Thus, much effort is being directed toward finding ways to increase apoptosis in prostate cancer.

In recent years, histone deacetylase (HDAC) inhibitors are emerging as an exciting new class of potential anticancer agents for the treatment of solid and hematologic malignancies, they cause hyperacetylation of histones, relaxation of chromatin structure, and activation of the transcription of certain regulatory genes (8). Butyrates are naturally occurring short-chain fatty acids leading to inhibition of tumor cell growth. It has been shown that butyrates can induce cell cycle arrest, differentiation, and apoptosis in many tumor cell types, while having a favorable safety profile in humans (9). In prostate cancer cells, as in other cell systems, induction of differentiation, growth arrest and apoptosis in response to sodium butyrate (SB) have been reported (10-12). However, the 
mechanism by which SB induces apoptosis is not completely understood. There are apparently many factors, including Bcl-2 family and caspase proteases, involved in the apoptotic process through the expression of genes, and the characterization of the function of these gene products will help to define the process of cell death at the molecular level (13).

In addition, deregulation of apoptosis may occur through death receptors. Death receptors belong to the tumor necrosis factor (TNF) superfamily of receptors and share a distinctive cytoplasmic domain called the death domain. The death receptor pathway of apoptosis has been repeatedly shown to be involved in chemotherapy-induced cell death. This has been well described for the antitumor molecule etoposide, which largely relies on this pathway to induce apoptosis (14).

This study was performed to further elucidate the mechanisms of the apoptotic pathway by SB in androgen-dependent LNCaP cells $(15,16)$, and androgen-refractory DU145 (17) and PC-3 (18) prostate cancer cells. We report that the exposure of prostate cancer cell lines to SB resulted in a dose-dependent growth inhibition and apoptosis. In addition, we characterized signaling mechanisms that mediate these biological effects. The ultimate goal of our study was to provide the rationale for the use of HDAC inhibitors as a new therapeutic modality in the treatment of prostate cancer in man.

\section{Materials and methods}

Cell culture and reagents. The LNCaP, PC-3 and DU145 cell lines were obtained from the American Type Culture Collection (Manassas, VA, USA). LNCaP cells were maintained in RPMI medium supplemented with $10 \%$ heat-inactivated fetal calf serum, $2 \mathrm{mM}$ L-glutamine, $100 \mathrm{U} / \mathrm{ml}$ penicillin $\mathrm{G}$ and $0.1 \mathrm{mM}$ non-essential amino acids in an atmosphere of $5 \% \mathrm{CO}_{2}$ at $37^{\circ} \mathrm{C}$. PC-3 and DU145 cells were maintained in $\mathrm{F}-12 \mathrm{~K}$ medium and minimum essential medium with the same supplements. Sodium butyrate (SB) was obtained from Sigma-Aldrich Chemie GmbH (Steinheim, Germany) and was dissolved in phosphate-buffered saline (PBS) without $\mathrm{Mg}^{2+}$ or $\mathrm{Ca}^{2+}[\operatorname{PBS}(-)]$.

Growth inhibition in cell culture. For determining cell proliferation, viable cell numbers were determined by the XTT assay using the Cell Proliferation kit II (Roche Diagnostics GmbH, Mannheim, Germany) (12). In brief, prostate cancer cells were grown in 96 -well plates $\left(1 \times 10^{3}\right.$ cells/well) for 2 days, and the medium was changed to various concentrations of sodium butyrate $(1,2$ or $3 \mathrm{mM})$ for periods of 2, 5 and 8 days, with a change of medium after 2 and 5 days. After 2, 5 and 8 days, $50 \mu \mathrm{l}$ of XTT labeling mixture was added to each well. After $4 \mathrm{~h}$ incubation at $37^{\circ} \mathrm{C}$, the difference in the absorption at $\mathrm{OD}_{450}$ and $\mathrm{OD}_{650}$ of the medium in each well was measured in a microplate reader. Standard curves were obtained by assaying known numbers of viable cells of each cell line.

Cell cycle and apoptosis analysis. Cells in medium were seeded on sterile glass slides, which were placed in $35-\mathrm{mm}$ dishes. The medium was changed $48 \mathrm{~h}$ later and cells were incubated in the presence of various concentrations of SB (1, 2 or $3 \mathrm{mM}$ ) for 7 days, with a change of medium after 3.5 days. Cells growing on the slides were fixed in $99 \%$ ethanol for

\section{LNCaP}

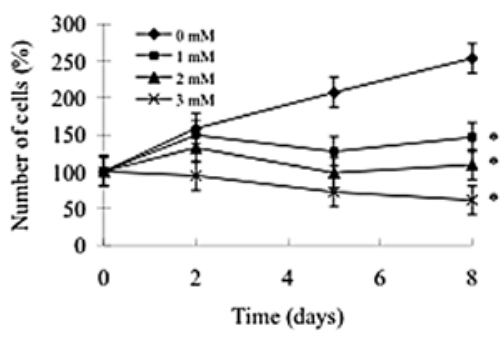

DU145

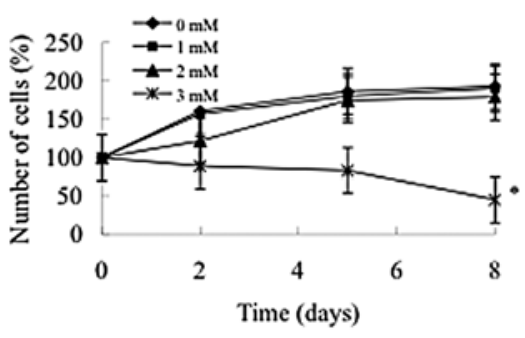

PC-3

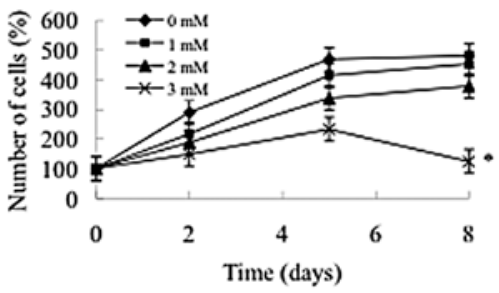

Figure 1. Effect of sodium butyrate (SB) on the growth of prostate cancer cell lines LNCaP, DU145 and PC-3. LNCaP, DU145 and PC-3 cells were treated with $0.2 \%$ PBS (-) or 1,2 and $3 \mathrm{mM} \mathrm{SB}$ for 8 days, cells were counted after 2, 5 and 8 days by the XTT assay. Data from three independent experiments are shown as means $\pm \mathrm{SD}$.

$30 \mathrm{~min}$, stained with a propidium iodide $(50 \mu \mathrm{g} / \mathrm{ml})$ solution containing $100 \mu \mathrm{g} / \mathrm{ml} \mathrm{RNase} \mathrm{A,} \mathrm{and} \mathrm{then} \mathrm{incubated} \mathrm{at} 37^{\circ} \mathrm{C}$ for $30 \mathrm{~min}$ in an incubator. The slides were rinsed with PBS (-), covered with mounting medium [30\% glycerin in PBS (-)] and a glass cover slide (Matsunami Techno, Tokyo, Japan). Cells that had adhered to the slides were scanned in a $5 \times 5 \mathrm{~mm}$ area with an LSC2 laser scanning cytometer (CompuCyte Corp, Cambridge, MA, USA). DNA histograms were analyzed using the WinCyte software (CompuCyte Corp) to evaluate the cell cycle components and count the cells with a fractional DNA content or 'sub-G1 peak', which would be typical for apoptosis (19). Apoptotic cells were examined under the laser scanning microscope Olympus BX51 (Olympus Optics Co, Tokyo, Japan) (20).

Western blot analysis. Cells were rinsed twice with PBS (-) and lysed with PBS (-) supplemented with 1\% NP-40, $20 \mathrm{mM}$ Tris (pH 8.0), $150 \mathrm{mM} \mathrm{NaCl}, 1 \mathrm{mM}$ EDTA, 10\% glycerol, $1 \mathrm{mM}$ PMSF, $5 \mathrm{mM}$ benzamidine, $2 \mathrm{mM} \mathrm{NaVO}_{4}, 10 \mu \mathrm{g} / \mathrm{ml}$ aprotinin, $1 \mu \mathrm{g} / \mathrm{ml}$ pepstatin, $0.1 \% \beta$-ME, $20 \mathrm{U} / \mathrm{ml}$ ulinastatin, $5 \mu \mathrm{g} / \mathrm{ml}$ leupeptin, $0.5 \mathrm{mM}$ DTT, $50 \mu \mathrm{g} / \mathrm{mM}$ AEBSF and $2 \mu \mathrm{g} / \mathrm{ml}$ antipain. The lysate was gently rotated for $30 \mathrm{~min}$ at $4^{\circ} \mathrm{C}$ and 

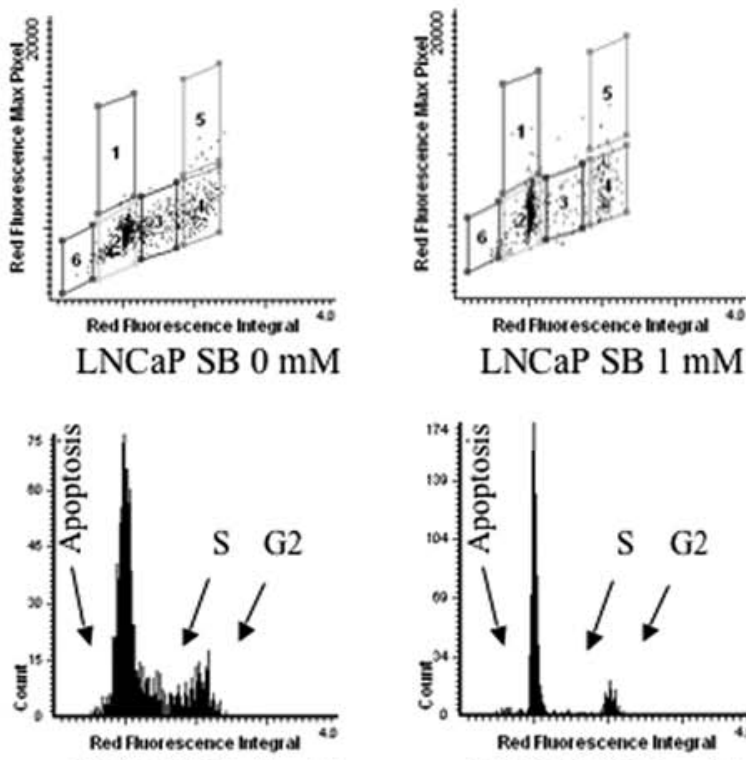

LNCaP SB $0 \mathrm{mM}$

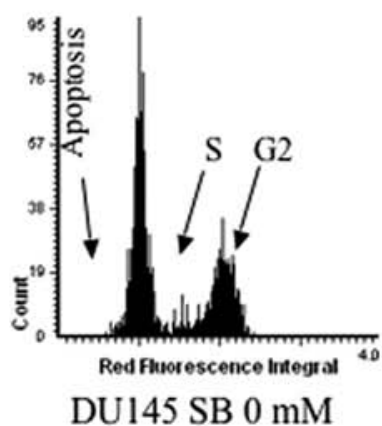

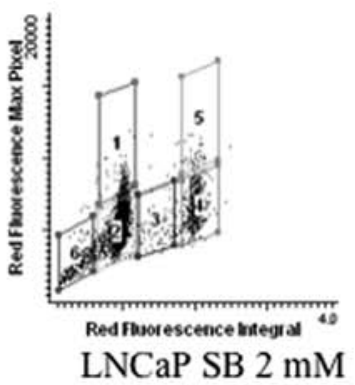

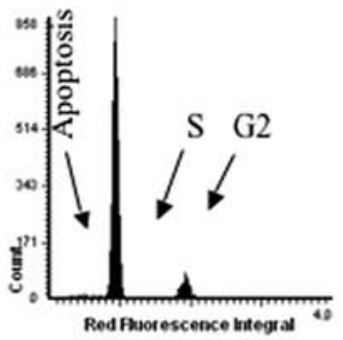

LNCaP SB $2 \mathrm{mM}$

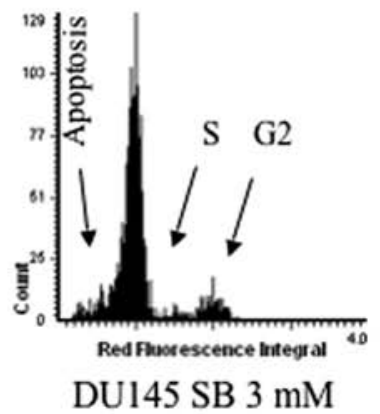

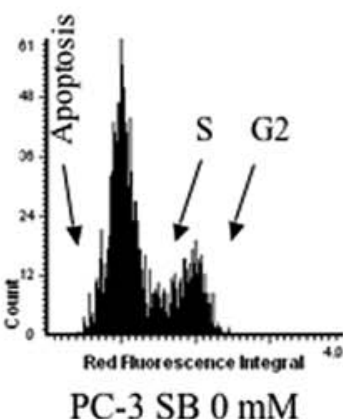

PC-3 SB $0 \mathrm{mM}$
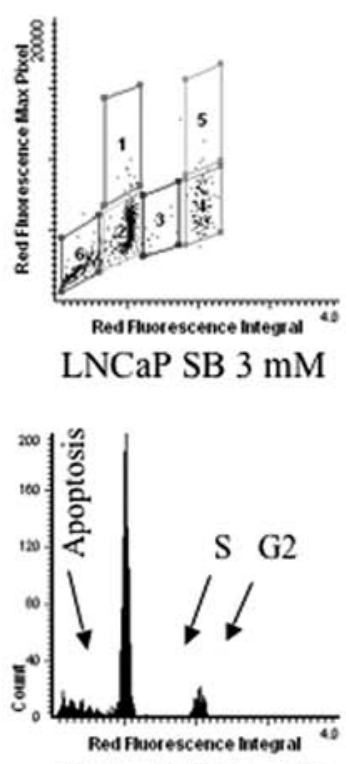

LNCaP SB $3 \mathrm{mM}$

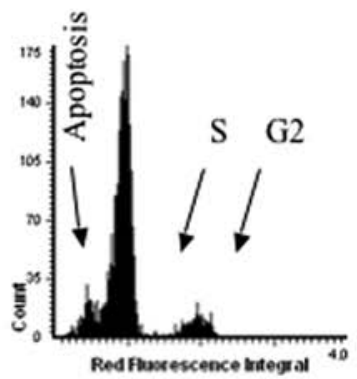

PC-3 SB $3 \mathrm{mM}$

Figure 2. Effect of sodium butyrate (SB) on the cell cycle and apoptosis in the prostate cancer cell lines, LNCaP, DU145 and PC-3. Cells were treated with $0.2 \%$ PBS (-) or 1, 2 and $3 \mathrm{mM} \mathrm{SB}$ for 7 days and stained for nuclear DNA with propidium iodide (PI). The intensity of PI staining was analyzed with the use of a microscope-based multiparameter laser scanning cytometer. 1, G0; 2, G1; 3, S; 4, G2; 5, M; 6, apoptosis.

centrifuged at $15000 \mathrm{rpm}$ for $30 \mathrm{~min}$ at $4^{\circ} \mathrm{C}$. The supernatant was analyzed for protein content using a BCA Protein Assay Kit (Pierce Biotechnology, Inc., Rockford, IL, USA). For gel electrophoresis, the supernatant containing $30 \mu \mathrm{g}$ of protein was electrophoresed on a $12.5 \%$ gradient SDS-polyacrylamide gel [PAGE] and blotted onto a polyvinylidenedifluoride (PVDF) membrane for $30 \mathrm{~min}$. The blotted membrane was treated with $5 \%$ skimmed milk in $25 \mathrm{mM}$ Tris, $150 \mathrm{mM} \mathrm{NaCl}$ and $0.1 \%$ Tween-20. Blots were incubated overnight at $4^{\circ} \mathrm{C}$ with the following primary antibodies: anti-p21 (1:200), anti-p27 (1:200), anti-CDK2 (1:500), anti-CDK4 (1:500), anti-CDK6 (1:500), anti-procaspase-3 (1:1000), anti-procaspase-7 (1:1000), anti-Fas (1:500), anti-FADD (1:250), anti-TRADD (1:250), anti-Bcl-2 (1:500), anti-Bcl-xL (1:500), anti-Bax (1:250), and anti-actin (1:2000). All primary antibodies were purchased from Santa Cruz Biotechnology Inc. (Santa Cruz, CA). The membranes were washed and incubated with polyclonal goat anti-mouse $\mathrm{IgG}$ or goat anti-rabbit IgG (Vector, Burlingame, CA, USA). The membrane was rinsed, treated with enhanced chemiluminescent (ECL) reagent (Amersham) and exposed to an RX100 film (Fuji). Bands were analyzed by a densitometer (ATTO Densitograph Software, Tokyo, Japan) (21).

Statistical analysis. The Student's t-test (JMP software) was used to analyze statistical differences between the SB-treated and control groups. The P-values were considered to be significant if $<0.05$.

\section{Results}

Effect of SB on prostate cancer cell line growth. The prostate cancer cell lines LNCaP, DU145 and PC-3 cells were treated with SB at various concentrations. After incubation for 2, 5 or 8 days, cells were harvested and viability was determined by the XTT assay. SB at $3 \mathrm{mM}$ completely inhibited growth of all cell lines used (Fig. 1). At lower concentrations of SB, the dose-response was somewhat different between the three cell lines, with LNCaP cells showing the highest sensitivity (Fig. 1).

Effect of SB on the cell cycle in prostate cancer cell. Cell cycle analysis using laser scanning cytometry showed that treatment of LNCaP cells with $3 \mathrm{mM} \mathrm{SB}$ for 7 days resulted in a $92 \%$ and $91 \%$ decrease in the fraction of cells in the $\mathrm{S}$ and $\mathrm{M}$ phases, respectively (Fig. 2 and Table I). SB also inhibited the progression from the G0/G1 to the $S$ phase and from the $\mathrm{G} 2$ to the $M$ phase in LNCaP cells, indicating that SB induced G1 and G2 arrest. Similar changes were observed in PC-3 and DU145 cells (Fig. 2 and Table II). These results suggest that the inhibition of cell cycle progression is the basis for the anti-cancer activity of SB in prostate cancer cells. 


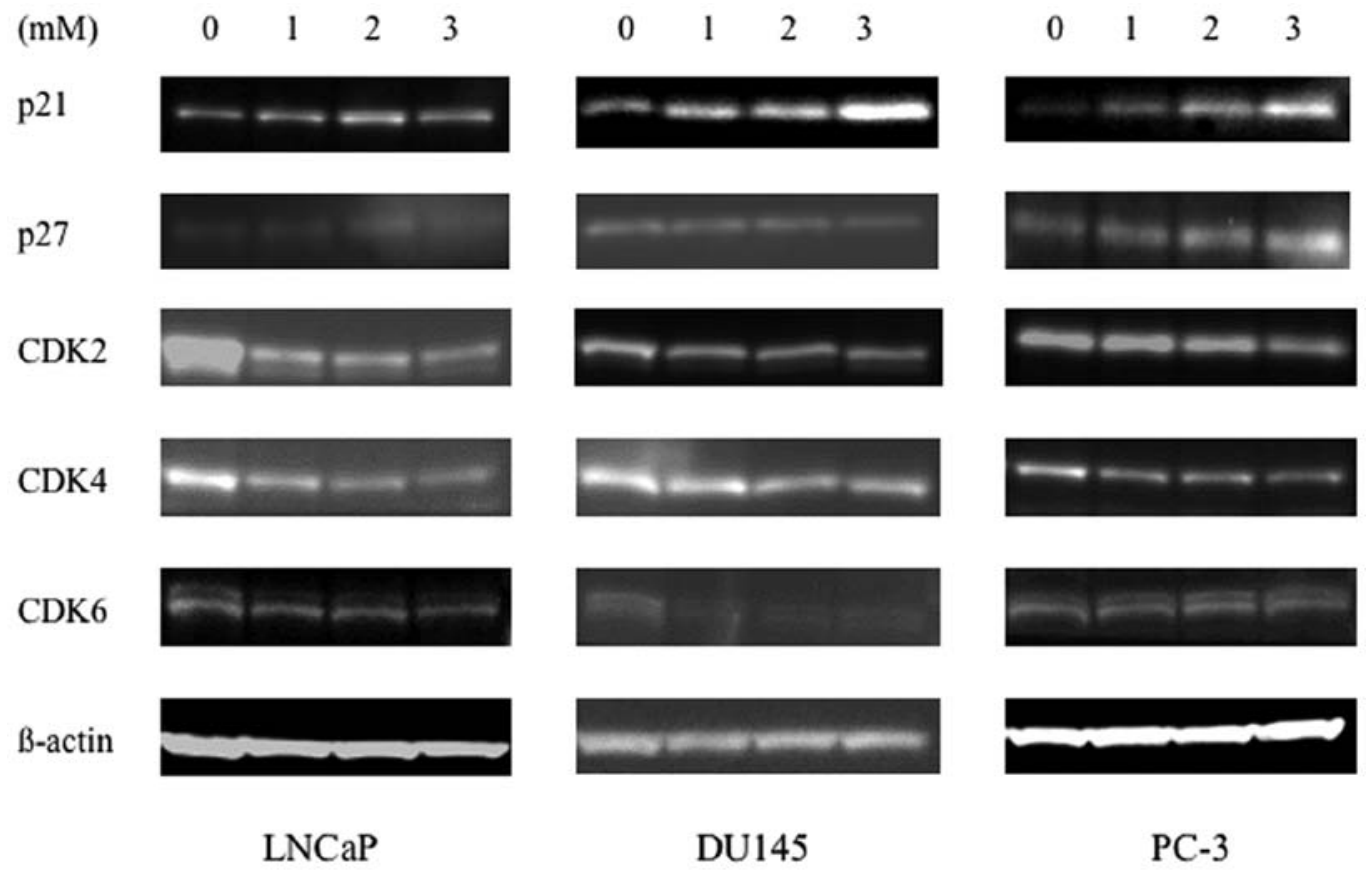

Figure 3. Effect of SB on the expression of cell cycle regulators. LNCaP, DU145 and PC-3 cells were treated with 0.2\% PBS (-) or 1, 2 and 3 mM SB for 7 days. Samples containing $30 \mu \mathrm{g}$ of total protein were used for Western blot analysis. Equal loading was confirmed by stripping immunoblots and reprobing them for $\beta$-actin. The experiments were repeated three times with similar results.

Table I. Effect of sodium butyrate on the cell cycle and apoptosis in LNCaP cells.

\begin{tabular}{lcccc}
\hline SB $(\mathrm{mM})$ & 0 & 1 & 2 & 3 \\
\hline G0 & $0.6 \pm 0.2$ & $0.9 \pm 0.5$ & $1.2 \pm 0.5$ & $0.5 \pm 0.1$ \\
G1 & $61.7 \pm 3.9$ & $73.1 \pm 2.5^{\mathrm{a}}$ & $79.2 \pm 1.3^{\mathrm{a}}$ & $70.3 \pm 2.2^{\mathrm{a}}$ \\
S & $13.4 \pm 1.4$ & $3.8 \pm 0.1^{\mathrm{a}}$ & $1.2 \pm 0.2^{\mathrm{a}}$ & $0.8 \pm 0.2^{\mathrm{a}}$ \\
G2 & $12.7 \pm 2.6$ & $13.8 \pm 0.7^{\mathrm{a}}$ & $10.4 \pm 1.0^{\mathrm{a}}$ & $11.6 \pm 0.6^{\mathrm{a}}$ \\
M & $2.2 \pm 0.5$ & $0.8 \pm 0.2^{\mathrm{a}}$ & $0.4 \pm 0.1^{\mathrm{a}}$ & $0.2 \pm 0.1^{\mathrm{a}}$ \\
Sub-G1 & $1.0 \pm 0.4$ & $2.8 \pm 0.1^{\mathrm{a}}$ & $4.4 \pm 0.8^{\mathrm{a}}$ & $15.1 \pm 1.5^{\mathrm{a}}$ \\
\hline
\end{tabular}

Data shown are the mean \pm SD percentages of cells in each cell cycle phase; ${ }^{a} \mathrm{P}<0.05$ for sodium butyrate (SB) vs. the control.

$S B$ affects the expression of $p 21, p 27$ and cycle-dependent kinases. Next, we investigated whether SB treatment alters the expression of regulatory proteins of the G1-S and G2-M checkpoint. Two CDK inhibitors (p21 and p27), CDK2, CDK4 and CDK6 were examined in LNCaP, DU145 and PC-3 cells after SB treatment by Western blot analysis. The results showed that the expression of $\mathrm{p} 21$ increased in a dosedependent manner in PC-3 and DU145 cells, but not in LNCaP cells. The expression of p27 was moderately increased in PC-3 and moderately decreased in DU145 cells treated with SB. The expression of CDK2, CDK4 and CDK6 decreased in a dose-dependent manner in all prostate cancer cell lines. The decrease in CDK2 expression was more pronounced than that of CDK4 and CDK6 (Fig. 3). These results showed that SB causes $\mathrm{G} 1$ and $\mathrm{G} 2$ arrest by up-regulation of p21 expression, and down-regulation of CDK2, CDK4 and CDK6 expression
Table II. Effect of sodium butyrate on the cell cycle and apoptosis in DU145 and PC-3 cells.

\begin{tabular}{lrrrrr}
\hline & \multicolumn{2}{c}{ DU145 } & & \multicolumn{2}{c}{ PC-3 } \\
\cline { 2 - 3 } \cline { 5 - 6 } SB $(\mathrm{mM})$ & \multicolumn{1}{c}{0} & 3 & & 0 & 3 \\
\hline G0 & $1.6 \pm 0.7$ & $1.2 \pm 0.4$ & & $0.6 \pm 0.2$ & $1.2 \pm 0.5$ \\
G1 & $54.8 \pm 2.9$ & $70.3 \pm 2.0^{\mathrm{a}}$ & & $51.5 \pm 2.7$ & $71.7 \pm 2.2^{\mathrm{a}}$ \\
S & $12.2 \pm 1.4$ & $4.2 \pm 0.4^{\mathrm{a}}$ & & $13.5 \pm 1.1$ & $3.9 \pm 0.3^{\mathrm{a}}$ \\
G2 & $23.4 \pm 0.6$ & $8.5 \pm 1.6^{\mathrm{a}}$ & & $16.8 \pm 2.1$ & $8.2 \pm 0.8^{\mathrm{a}}$ \\
M & $3.3 \pm 0.5$ & $1.0 \pm 0.2^{\mathrm{a}}$ & $1.5 \pm 0.4$ & $0.8 \pm 0.3^{\mathrm{a}}$ \\
Sub-G1 & $0.4 \pm 0.1$ & $8.7 \pm 0.5^{\mathrm{a}}$ & $1.7 \pm 0.3$ & $9.7 \pm 0.8^{\mathrm{a}}$ \\
\hline
\end{tabular}

Data shown are the mean \pm SD percentages of cells in each cell cycle phase; ${ }^{a} \mathrm{P}<0.05$ for sodium butyrate $(\mathrm{SB})$ vs. the control.

in PC-3 and DU145 cells. In LNCaP cells, down-regulation of the CDKs appears to play an important role in G1 arrest.

SB induces apoptosis in all prostate cancer cell lines. $\mathrm{LNCaP}$, DU145 and PC-3 cells treated with $3 \mathrm{mM}$ SB for 7 days exhibited a sub-G1 peak by laser scanning cytometry (Fig. 2). Analysis of cell morphology under laser scanning microscope detected condensed and fragmented nuclei (Fig. 4). These results showed that SB induced apoptosis in these prostate cancer cell lines.

Role of caspase activation in SB-induced apoptosis. Caspases play an important role as mediators of apoptotic signals, and their activation is considered a hallmark of apoptosis. We analyzed caspase- 3 and caspase-7 in LNCaP, DU145 and PC-3 
LNCaP
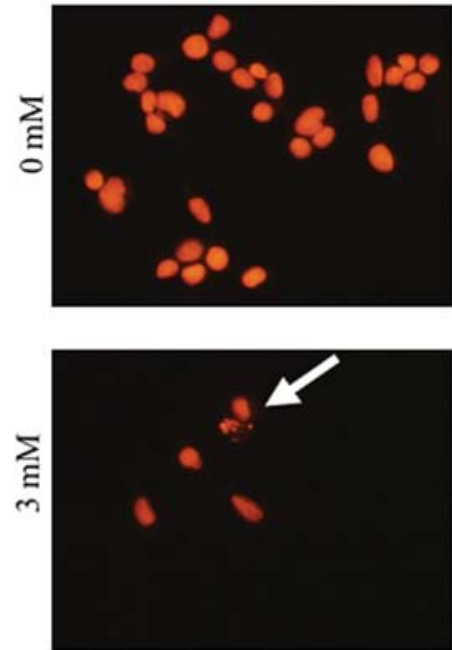

DU145
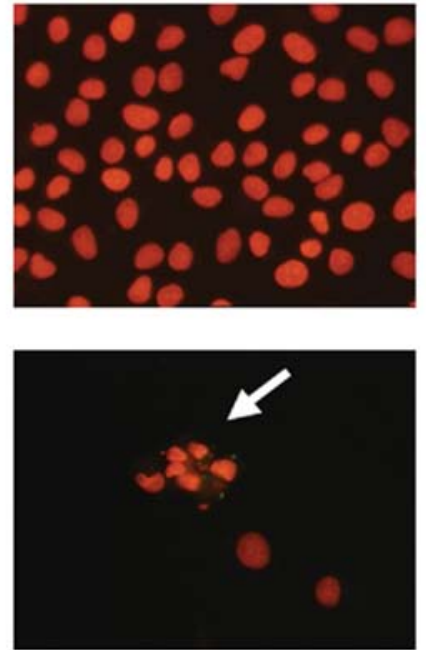

PC-3
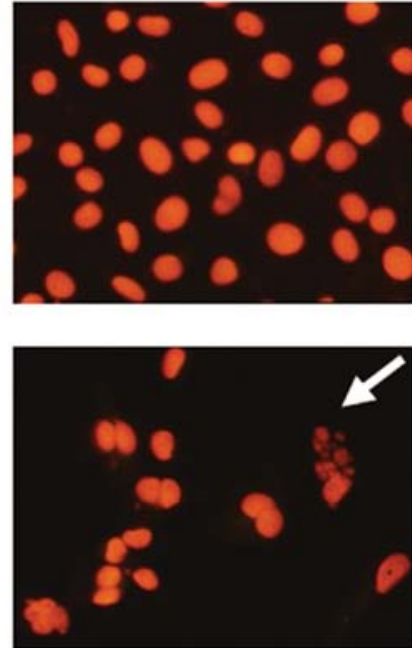

Figure 4. Analysis of apoptosis in LNCaP, DU145 and PC-3 cells by laser scanning microscope. LNCaP, DU145 and PC-3 cells were treated with $0.2 \%$ PBS (-) or 1,2 and $3 \mathrm{mM}$ sodium butyrate (SB) for 7 days and analyzed for apoptosis and necrosis (arrows) by laser scanning microscope.

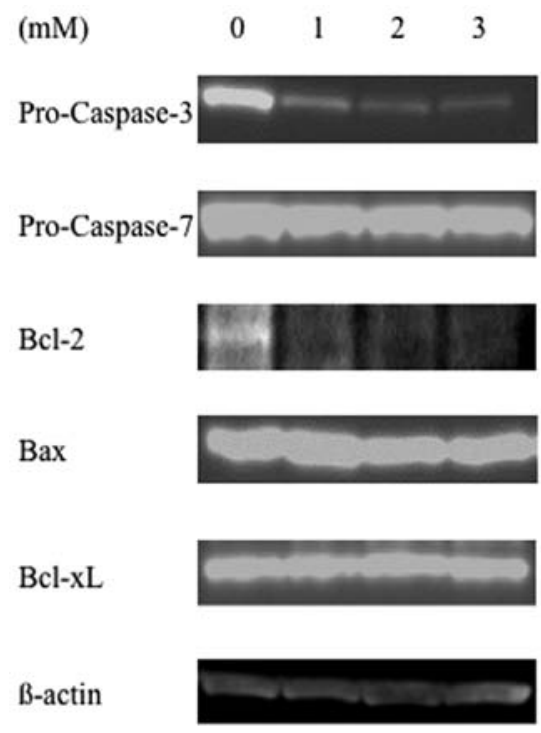

LNCaP

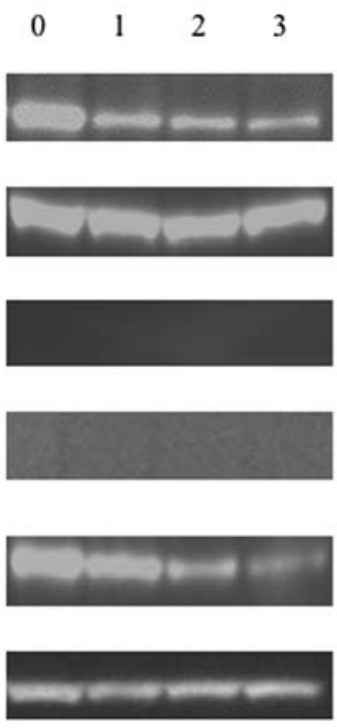

DU145
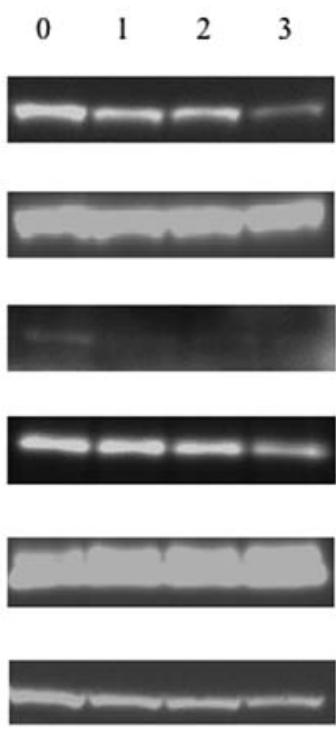

PC-3

Figure 5. Effect of SB treatment on the expression of procaspse-3, procaspase-7, Bcl-2, Bcl-xL and Bax in LNCaP, DU145 and PC-3 cells. LNCaP, DU145 and PC-3 cells were treated with $0.2 \%$ PBS (-) or 1,2 and 3 mM SB for 7 days, the expression of procaspse-3, procaspase-7, Bcl-2, Bcl-xL and Bax were determined by Western blot analysis. Equal loading was confirmed by stripping immunoblots and reprobing them for $\beta$-actin. Representative immunoblots of three independent experiments with similar results.

cells after treatment with SB for 7 days. We found that the expression of procaspase-3 was significantly down-regulated in all these cell lines, while the expression of procaspase-7, which remained unchanged (Fig. 5). These results suggest that SB-induced apoptosis of prostate cancer cells is mediated by caspase- 3 but not caspase-7.

Effect of SB on the expression of mitochondria-dependent apoptotic proteins. We measured the expression of mitochondria-associated proteins (Bcl-2, Bcl-xL and Bax) known to play a role in the apoptotic process. As shown in Fig. 5, SB treatment caused a significant dose-dependent decrease in the expression of Bcl-2 and Bcl-xL. Furthermore, the protein expression of Bcl-2 was significantly decreased in PC-3 and LNCaP cells, Bcl-xL protein expression was significantly decreased in DU145 cells, and the expression of Bax was not significantly changed in LNCaP and PC-3 cells. In DU145 cells, Western blot analysis did not reveal the presence of Bcl-2 or Bax. These data suggest that SB induces apoptosis of prostate cancer cells through the Bcl-2-mediated and Bcl-xLmediated apoptosis pathways.

Effect of $S B$ on the expression of the death domain receptordependent apoptotic proteins in prostate cancer cells. Next, 


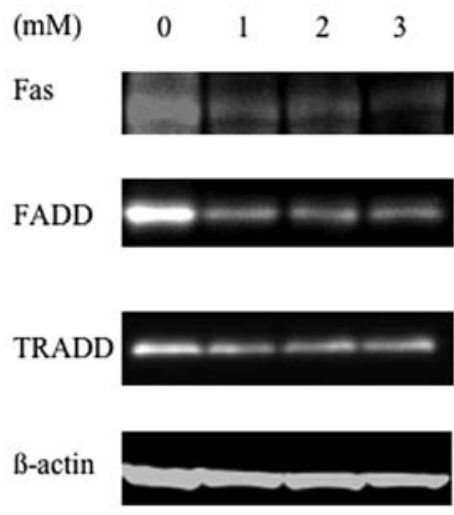

LNCaP

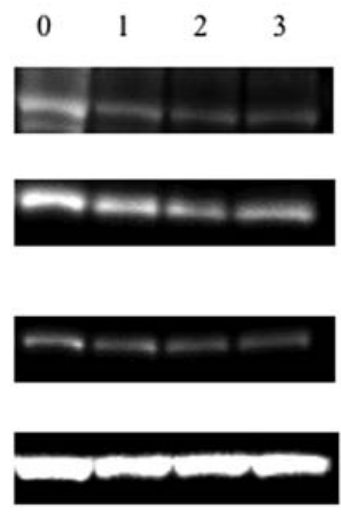

DU145
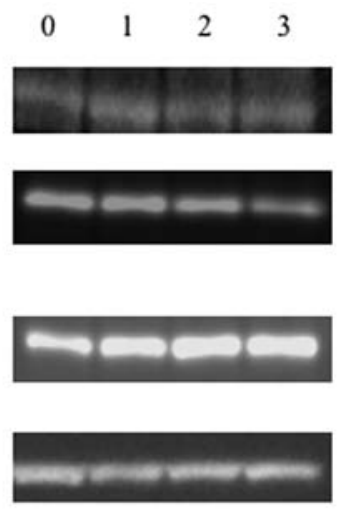

PC-3

Figure 6. Effect of SB treatment on the expression of Fas, FADD and TRADD in LNCaP, DU145 and PC-3 cells. LNCaP, DU145 and PC-3 cells were treated with $0.2 \%$ PBS (-) or 1, 2 and 3 mM SB for 7 days and the expression of Fas, FADD, TRADD were determined by Western blot analysis. Equal loading was confirmed by stripping immunoblots and reprobing them for $\beta$-actin. The immunoblots are representative of three independent experiments with similar results.

we determined the effect of SB on the expression of a death receptor protein (Fas) and of two death adaptor proteins (FADD and TRADD). As shown in Fig. 6, DU145, PC-3 and LNCaP cells treated with $\mathrm{SB}$ exhibited no significant changes in the expression of TRADD protein. In contrast, expression of Fas and FADD proteins were dose-dependently decreased by SB treatment. These data suggest that SB does not induce apoptosis of prostate cancer cells through the Fas-mediated apoptosis pathway. The slight reduction in Fas expression caused by SB could not be explained.

\section{Discussion}

HDAC inhibitors are emerging as a promising new therapeutic tool for the treatment of a variety of human tumors. Some, like depsipeptide, are under clinical trials for solid tumors and hematologic malignancies $(22,23)$. The effect of HDAC inhibitors on the viability of prostate cancer cells has been poorly studied. Several reports have demonstrated that HDAC inhibitors decrease cell proliferation in various prostate cancer lines $(11,12,24-27)$ and a few studies have shown the induction of apoptosis after exposure to HDAC inhibitors for 2 or more days $(11,12,26)$. In the present study, using LNCaP, DU145 and PC-3 prostate cells, we confirmed inhibition of proliferation of prostate cells by SB. SB causes a G1 cell cycle arrest via induction of p21 in DU145 and PC-3 cells together with an inhibition in cycle-dependent kinase (CDK2, CDK4 and CDK6) activity as an underlying mechanism for growth inhibition in all prostate cancer cell lines studied. Furthermore, SB induces apoptosis by mechanisms involving or mediated by Bcl-2 and Bcl-xL.

Cell cycle progression is regulated by the sequential activation of cyclin-dependent kinases (CDKs) that are subject to negative regulation by CDK inhibitors (CDKIs), such as p16 p18 p19 p21, and p27. CDKIs are tumor suppressor proteins that down-regulate the cell cycle progression by binding with active CDK-cyclin complexes and thereby inhibiting their kinase activities (28-30). It is known that p21 can induce cell cycle arrest in G1 and/or G2-M by inhibiting kinase activity of CDKs, as it is regarded as a universal inhibitor of CDKs (31). Cell cycle analysis data showed that SB caused G2-M arrest along with G1 arrest in cell cycle progression of prostate cancer cells. Furthermore, a mechanistic investigation showed that SB-induced G1 and G2 arrest in PC-3 and DU145 cells is primarily mediated via up-regulation of $\mathrm{p} 21$. As progression of cells to $\mathrm{Gl}$ and entry into the $\mathrm{S}$ phase of the cell cycle is regulated by two distinct CDKs, CDK4 (or CDK6) and CDK2 (32), concomitant with CDKI induction, we also observed a decrease in the protein levels of CDK2, CDK4 and CDK6. Among the CDKs that regulate cell cycle progression, CDK1 and CDK2 kinases are activated primarily in association with cyclin $\mathrm{A}$ and $\mathrm{B} 1$ in the G2-M phase progression (33). In this study, we found that CDK2 protein was decreased in a dose-dependent manner following SB treatment and the decrease in CDK2 expression was more pronounced than that of CDK4 and CDK6.

p27 is also an important regulator of the G1-S phase transition and it binds and inhibits cyclin E/CDK2, thereby negatively regulating $\mathrm{S}$ phase entry (34). In this study, SB moderately increased p27 expression in PC-3 but moderately decreased it in DU145 cells. The increase in the expression of CDKIs by SB may also have a direct relevance in prostate cancer growth and progression, as a decreased p27 expression in prostatic carcinomas has been associated with an aggressive phenotype and poor prognosis, while a failure of a response to irradiation in prostate cancer patients has been linked to the loss of p21 function (35). Loss of p27 protein has been associated with development and progression of various cancers, including breast, colorectal and lung cancer (36). Many reports also suggest that cell cycle arrest is often followed by or associated with apoptotic death of cancer cells caused by various cancer therapeutic agents (37). Therefore, agents that can induce apoptosis may be useful in the therapy of cancer $(37,38)$. Our data show that SB can induce apoptosis in prostate cancer cells.

The two major apoptotic pathways are the mitochondrialdependent pathway and the death receptor pathway (39). Fas (CD95/Apo-1) belongs to the tumor necrosis factor (TNF) receptor family, and the Fas signaling pathway is the best characterized death receptor-mediated pathway. Multivalent crosslinking of the Fas receptor, as a result of FasL binding to pre-associated Fas receptor trimers, triggers the recruitment of a set of effector proteins to the receptor, resulting in the formation of the death-inducing signaling complex. The death-inducing signaling complex is composed of intracellular signaling 
proteins including the Fas-associated death domain (FADD/ MORT1), a death domain-containing an adaptor protein, and caspase-8 (also known as FLICE/MACH). Upon recruitment to the death-inducing signaling complex, caspase- 8 is autoproteolytically cleaved and activated. Activated caspase- 8 in turn directly activates caspase- 3 , leading to execution of apoptosis (40). Although the expression of Fas is widespread, most cell types are resistant to apoptosis mediated through this pathway (41). Prostate cancer cells express Fas, but are strongly resistant to Fas-mediated apoptosis (42), which may be due to the expression of dominant-negative regulatory proteins (43). Our results indicated that SB did not enhance the expression of Fas, but rather suppressed it slightly. In the current study, SB induced apoptosis in prostate cancer cells, in agreement with Owen-Schaub et al (41), who reported that Fas expression is necessary but not sufficient to induce apoptosis through this pathway. We also found that it was difficult to induce prostate cancer cells to undergo Fas-mediated apoptosis.

$\mathrm{Bcl}-2$ is an antiapoptotic protein present on the mitochondrial membrane. By binding and inactivating the apoptotic protein Bax, Bcl-2 blocks the release of cytochrome $\mathrm{c}$ from the mitochondria and prevents the activation of caspase- 9 , which would lead to the activation of the intrinsic apoptotic pathway (44). Down-regulation of antiapoptotic proteins and up-regulation of pro-apoptotic proteins of the Bcl-2/Bax family is quite common during cell differentiation (45). In the present study, we were unable to detect the expression of Bcl-2 and Bax in DU145 cells. It has recently been shown that PC-3 and LNCaP cells express Bcl-2 and Bax, but DU145 cells do not (46). In PC-3 and LNCaP cells, the expression of Bcl-2 was significantly down-regulated, although the expression of Bax was not significantly changed, resulting in an increased Bax/ Bcl-2 ratio, which favors the pro-apoptotic action of Bax (47). $\mathrm{Bcl}-\mathrm{xL}$ is a member of the Bcl-2 family. In PC-3 and LNCaP cells, the expression of Bcl-xL was not significantly altered, whereas in DU145 cells, the expression of Bcl-xL was significantly down-regulated. These data indicate that SB causes apoptosis involving Bcl-2 and Bcl-xL.

Caspases plays a central role in many forms of apoptosis. These enzymes are synthesized as inactive zymogens that must be cleaved after conserved aspartate residues to be activated. Both the mitochondrial and death receptor pathways have been shown to trigger caspase activation in cells undergoing apoptosis (48). Treatment of cells with SB resulted in a significant decrease in the protein expression of procaspase- 3 but not of procaspase-7. These results suggest that SB-induced Bcl-2 and $\mathrm{Bcl}-\mathrm{xL}$ signaling in prostate cancer cells is mediated by caspase-3, but not caspase- 7 .

In summary, we have demonstrated that the prostate cancer cell lines used herein were sensitive to SB. We identified one distinct signaling pathway involved in SB-mediated cell growth arrest at the G1 and G2 phase with induction of apoptosis. The ultimate goal of our study is to provide the rationale for the use of HDAC inhibitors as a new therapeutic modality in the treatment of prostate cancer in humans.

\section{Acknowledgements}

We thank Ms. Chihiro Sato and Ms. Akiko Kawara-Yamazaki for technical assistance.

\section{References}

1. Parker SL, Davis KJ, Wingo PA, Ries LA and Heath CW Jr: Cancer statistics by race and ethnicity. CA Cancer J Clin 48: 31-48, 1998.

2. Jemal A, Murray T, Samuels A, Ghafoor A, Ward E and Thun MJ: Cancer statistics, 2003. CA Cancer J Clin 53: 5-26, 2003.

3. Martel CL, Gumerlock PH, Meyers FJ and Lara PN: Current strategies in the management of hormone refractory prostate cancer. Cancer Treat Rev 29: 171-187, 2003.

4. Hyer ML, Voelkel-Johnson C, Rubinchik S, Dong J and Norris JS: Intracellular Fas ligand expression causes Fas-mediated apoptosis in human prostate cancer cells resistant to monoclonal antibody-induced apoptosis. Mol Ther 2: 348-358, 2000.

5. Bruckheimer EM and Kyprianou N: Apoptosis in prostate carcinogenesis. A growth regulator and a therapeutic target. Cell Tissue Res 301: 153-162, 2000.

6. Peehl DM: Primary cell cultures as models of prostate cancer development. Endocr Relat Cancer 12: 19-47, 2005.

7. Gurumurthy S, Vasudevan KM and Rangnekar VM: Regulation of apoptosis in prostate cancer. Cancer Metastasis Rev 20: 225-243, 2001.

8. Xiao H, Hasegawa T, Miyaishi O, Ohkusu K and Isobe K: Sodium butyrate induces NIH3T3 cells to senescence-like state and enhances promoter activity of $\mathrm{p} 21 \mathrm{WAF} / \mathrm{CIP} 1$ in $\mathrm{p} 53$-independent manner. Biochem Biophys Res Commun 237: 457-460, 1997.

9. Chen JS, Faller DV and Spanjaard RA: Short-chain fatty acid inhibitors of histone deacetylases: promising anticancer therapeutics? Curr Cancer Drug Targets 3: 219-236, 2003.

10. Carducci MA, Nelson JB, Chan-Tack KM, et al: Phenylbutyrate induces apoptosis in human prostate cancer and is more potent than phenylacetate. Clin Cancer Res 2: 379-387, 1996.

11. Gleave ME, Sato N, Sadar M, Yago V, Bruchovsky N and Sullivan L: Butyrate analogue, isobutyramide, inhibits tumor growth and time to androgen-independent progression in the human prostate LNCaP tumor model. J Cell Biochem 69: 271-281, 1998.

12. Maier S, Reich E, Martin R, et al: Tributyrin induces differentiation, growth arrest and apoptosis in androgen-sensitive and androgen-resistant human prostate cancer cell lines. Int J Cancer 88: 245-251, 2000.

13. Adams JM and Cory S: Life-or-death decisions by the Bcl-2 protein family. Trends Biochem Sci 26: 61-66, 2001.

14. Petak I and Houghton JA: Shared pathways: death receptors and cytotoxic drugs in cancer therapy. Pathol Oncol Res 7: 95-106, 2001.

15. Horoszewicz JS, Leong SS, Chu TM, et al: The LNCaP cell line-a new model for studies on human prostatic carcinoma. Prog Clin Biol Res 37: 115-132, 1980.

16. Horoszewicz JS, Leong SS, Kawinski E, et al: LNCaP model of human prostatic carcinoma. Cancer Res 43: 1809-1818, 1983.

17. Mickey DD, Stone KR, Wunderli H, Mickey GH and Paulson DF: Characterization of a human prostate adenocarcinoma cell line (DU 145) as a monolayer culture and as a solid tumor in athymic mice. Prog Clin Biol Res 37: 67-84, 1980.

18. Kaighn ME, Narayan KS, Ohnuki Y, Lechner JF and Jones LW: Establishment and characterization of a human prostatic carcinoma cell line (PC-3). Invest Urol 17: 16-23, 1979.

19. Bedner E,Li X, Gorczyca W, Melamed MR and DarzynkiewiczZ: Analysis of apoptosis by laser scanning cytometry. Cytometry 35: 181-195, 1999.

20. Shibata MA, Ito Y, Morimoto J and Otsuki Y: Lovastatin inhibits tumor growth and lung metastasis in mouse mammary carcinoma model: a p53-independent mitochondrial-mediated apoptotic mechanism. Carcinogenesis 25: 1887-1898, 2004.

21. Klisovic DD, Katz SE, Effron D, et al: Depsipeptide (FR901228) inhibits proliferation and induces apoptosis in primary and metastatic human uveal melanoma cell lines. Invest Ophthalmol Vis Sci 44: 2390-2398, 2003.

22. Piekarz RL, Robey R, Sandor V, et al: Inhibitor of histone deacetylation, depsipeptide (FR901228), in the treatment of peripheral and cutaneous T-cell lymphoma: a case report. Blood 98: 2865-2868, 2001.

23. Sandor V, Bakke S, Robey RW, et al: Phase I trial of the histone deacetylase inhibitor, depsipeptide (FR901228, NSC 630176), in patients with refractory neoplasms. Clin Cancer Res 8: 718-728, 2002.

24. Suenaga M, Soda H, Oka M, et al: Histone deacetylase inhibitors suppress telomerase reverse transcriptase mRNA expression in prostate cancer cells. Int J Cancer 97: 621-625, 2002. 
25. Butler LM, Agus DB, Scher HI, et al: Suberoylanilide hydroxamic acid, an inhibitor of histone deacetylase, suppresses the growth of prostate cancer cells in vitro and in vivo. Cancer Res 60: 5165-5170, 2000.

26. Ellerhorst J, Nguyen T, Cooper DN, Estrov Y, Lotan D and Lotan R: Induction of differentiation and apoptosis in the prostate cancer cell line LNCaP by sodium butyrate and galectin-1. Int J Oncol 14: 225-232, 1999.

27. Sasakawa Y, Naoe Y, Inoue T, et al: Effects of FK228, a novel histone deacetylase inhibitor, on tumor growth and expression of p21 and c-myc genes in vivo. Cancer Lett 195: 161-168, 2003.

28. Grana $X$ and Reddy EP: Cell cycle control in mammalian cells: role of cyclins, cyclin dependent kinases (CDKs), growth suppressor genes and cyclin-dependent kinase inhibitors (CKIs) Oncogene 11: 211-219, 1995.

29. Morgan DO: Principles of CDK regulation. Nature 374: 131-134, 1995.

30. Hunter T and Pines J: Cyclins and cancer. II: Cyclin D and CDK inhibitors come of age. Cell 79: 573-582, 1994.

31. Sherr CJ and Roberts JM: CDK inhibitors: positive and negative regulators of G1-phase progression. Genes Dev 13: 1501-1512, 1999.

32. Ortega S, Malumbres M and Barbacid M: Cyclin D-dependent kinases, INK4 inhibitors and cancer. Biochim Biophys Acta 1602: 73-87, 2002

33. Wu ZZ, Chien CM, Yang SH, et al: Induction of G2/M phase arrest and apoptosis by a novel enediyne derivative, THDA, in chronic myeloid leukemia (K562) cells. Mol Cell Biochem 292: 99-105, 2006.

34. Hengst $L$ and Reed SI: Translational control of $\mathrm{p} 27 \mathrm{Kip} 1$ accumulation during the cell cycle. Science 271: 1861-1864, 1996.

35. Cheng L, Lloyd RV, Weaver AL, Pisansky TM, Cheville JC Ramnani DM, Leibovich BC, Blute ML, Zincke $\mathrm{H}$ and Bostwick DG: The cell cycle inhibitors p21WAF1 and p27KIP1 are associated with survival in patients treated by salvage prostatectomy after radiation therapy. Clin Cancer Res 6: 1896-1899, 2000.

36. Sgambato A, Cittadini A, Faraglia B and Weinstein IB: Multiple functions of $\mathrm{p} 27(\mathrm{Kip} 1)$ and its alterations in tumor cells: a review. J Cell Physiol 183: 18-27, 2000.
37. Singh RP, Dhanalakshmi S and Agarwal R: Phytochemicals as cell cycle modulators: a less toxic approach in halting human cancers. Cell Cycle 1: 156-161, 2002.

38. Gastman BR: Apoptosis and its clinical impact. Head Neck 23: 409-425, 2001.

39. Budihardjo I, Oliver H,Lutter M, Luo X and Wang X: Biochemical pathways of caspase activation during apoptosis. Annu Rev Cell Dev Biol 15: 269-290, 1999.

40. Peter ME and Krammer PH: The CD95(APO-1/Fas) DISC and beyond. Cell Death Differ 10: 26-35, 2003.

41. Owen-Schaub LB, Radinsky R, Kruzel E, Berry K and Yonehara S: Anti-Fas on nonhematopoietic tumors: levels of Fas/APO-1 and bcl-2 are not predictive of biological responsiveness. Cancer Res 54: 1580-1586, 1994

42. Hedlund TE, Duke RC, Schleicher MS and Miller GJ: Fas-mediated apoptosis in seven human prostate cancer cell lines: correlation with tumor stage. Prostate 36: 92-101, 1998.

43. Rokhlin OW, Bishop GA, Hostager BS, et al: Fas-mediated apoptosis in human prostatic carcinoma cell lines. Cancer Res 57: 1758-1768, 1997.

44. Los M, Wesselborg S and Schulze-Osthoff K: The role of caspases in development, immunity, and apoptotic signal transduction: lessons from knockout mice. Immunity 10: 629-639, 1999.

45. Xu HM, Tepper CG, Jones JB, Fernandez CE and Studzinski GP 1,25-Dihydroxyvitamin D3 protects HL60 cells against apoptosis but down-regulates the expression of the bcl-2 gene. Exp Cell Res 209: 367-374, 1993.

46. Haldar S, Chintapalli J and Croce CM: Taxol induces bcl-2 phosphorylation and death of prostate cancer cells. Cancer Res 56: 1253-1255, 1996.

47. Chopin V, Toillon RA, Jouy N and Le Bourhis X: Sodium butyrate induces p53-independent, Fas-mediated apoptosis in MCF-7 human breast cancer cells. Br J Pharmacol 135: 79-86, 2002.

48. Utz PJ and Anderson P: Life and death decisions: regulation of apoptosis by proteolysis of signaling molecules. Cell Death Differ 7: 589-602, 2000. 